\title{
BIAYA STANDAR SEBAGAI ALAT PENGENDALIAN BIAYA PRODUKSI PADA USAHA PAVING BLOCK CV. BATAKO ANUGERAH BAUBAU
}

\author{
Nining Asniar Ridzal \\ Program StudiAkuntansi, FakultasEkonomi \\ Universitas Muhammadiyah Buton, Baubau, Indonesia \\ e-mail: nining.asniar@umbuton.ac.id
}

\begin{abstract}
ABSTRAK
Setiap perusahaan dalam operasinya mengharapkan keuntungan yang optimal. Untuk itu diperlukan pengorbanan biaya. Agar pengeluaran biaya ini efektif maka harus ada pengendalian biaya. Salah satu alat pengendalian biaya yang dapat digunakan adalah sistem biaya standar. Dengan sistem biaya standar, maka penyimpangan biaya yang terjadi akan mudah dianalisis. Tujuan penelitian ini adalah untuk mengetahui jumlah selisih antara biaya standar yang ditetapkan oleh perusahaan dengan biaya yang sesungguhnya terjadi. Analisis data menggunakan analisis varians.

Berdasarkan hasil analisis dapat disimpulkan bahwa pada analisis varians biaya bahan baku, biaya tenaga kerja, dan biaya overhead pabrik menunjukkan adanya selisih lebih, karena biaya standar lebih tinggi dari biaya sesungguhnya. Untuk menghindari terjadinya pemborosan dan persediaan yang menumpuk, maka disarankan agar pihak manajemen dalam melakukan pembelian dan pemakaian bahan baku, pemakaian tenaga kerja, dan overhead pabrik perlu pengawasan yang lebih efektif dan dalam penetapan biaya standar tetap memperhitungkan biaya-biaya historis.
\end{abstract}

\section{Kata Kunci : Biaya Standar, Pengendalian Biaya, Biaya Produksi}

\begin{abstract}
Each company in its operations expects optimal profits. For that a cost this expenditure is effective, there must be cost control. One of the cost control tools that can be used is the standard cost system. With a standard cost system, the cost deviations thar occur will be aesilyanalyzed. The purpose of this study is to find out the difference between the standard costs set by the company and the actual costs incurred. Data analysis using analysis of variance.

Based on the results of the analysis it can be cocluded that the analysis of the variance of raw material costs, labor costs, and factory overhead costs indicates that there is more difference, because standard costs are higher than the actual costs. To avoid wastefulness and accumulated inventory, it is recommended that management in purchasing and using raw materials, using labor, and factory overhead need more effective supervision and in setting standard costs still taking into account historical costs.
\end{abstract}

Keywords : Standard Cost, Control Cost, Production CosT 


\section{PENDAHULUAN}

Terlibatnya perusahaan pemerintah dan swasta dalam pembangunan fisik dan non fisik sangat diharapkan selain akan menunjang pembangunan ekonomi, teknologi dan sumber daya manusia, juga akan memberikan pengaruh besar terhadap timbulnya atau berkembangnya perusahaan bahan bangunan seperti perusahaan pembuatan batu merah, pabrik semen, perusahaan paving block dan lain sebagainya. Dimana perusahaan ini memerlukan biaya sebagai penunjang aktivitasnya. Karena itu pengawasan terhadap biaya perlu mendapat perhatian yang serius.

Dalam kegiatan berproduksi perusahaan harus mengeluarkan sejumlah biaya yang diharapkan akan memberikan kontribusi yang lebih besar. Harga pokok produksi misalnya perusahaan membutuhkan informasi tentang biaya-biaya yang membentuk harga pokok produksi itu sendiri. Biaya produksi adalah biaya yang dikeluarkan untuk menghasilkan suatu barang. Biaya produksi merupakan biaya yang berkaitan dengan pembuatan barang atau penyediaan jasa. Biaya-biaya yang membentuk harga pokok barang yang dihasilkan meliputi biaya bahan baku, biaya tenaga kerja langsung, dan biaya overhead pabrik [1].

Untuk memperoleh laba, maka pimpinan perusahaan harus memberikan perhatian besar untuk memperbaiki kondisi intern perusahaan.Penentuan biaya produksi sangat penting sehingga perusahaan tidak salah menentukan harga jual dari produk yang dihasilkan. Untuk itu pengendalian biaya produksi harus dilakukan sehingga benar-benar biaya yang dikeluarkan adalah biaya-biaya yang membentuk biaya produk. Metode yang dapat digunakan adalah biaya standar. Biaya standar adalah biaya yang ditentukan dimuka yang merupakan jumlah biaya yang seharusnya dikeluarkan untuk membuat satuan produk atau untuk membiayai kegiatan tertentu di bawah asumsi kegiatan ekonomi, efisiensi dan faktor-faktor lain [2]. Adapun biaya standar tersebut adalah biaya bahan baku standar, biaya tenaga kerja standar, dan biaya overhead pabrik standar [3]. Penetapan standar yang tepat untuk biaya produksi sangat penting karena akurasi standar menentukan keberhasilan sistem biaya standar. Hal tersebut dapat dijadikan sebagai alat pengendalian biaya yaitu mencatat biaya produksi standard an biaya yang sesugguhnya terjadi kemudian membandingkan kedua biaya tersebut dan menyajikan analisis penyimpangannya. Salah satu cara mengetahui jumlah penyimpangan yag terjadi dalam biaya produksi adalah dengan menggunakan analisis varians. Varians yang tidak ditoleransi (unvaforable $(U)$ variance) sedangkan varians yang ditoleransi (favorable $(F)$ 
Variance) muncul ketika biaya actual lebih kecil daripada biaya standar yang ditetapkan [4].

CV. Batako Anugerah yang bergerak dalam usaha memproduksi bahan bangunan dimana salah satu hasil produksinya adalah paving block. CV.Batako Anugerah Baubau dalam menetapkan biaya standar sebagai alat pengendalian biaya hanya berdasarkan pada pengalaman dan kebiasaan. Konsekuensi dari cara pengendalian ini adalah pihak perusahaan tidak dapat mengontrol pengeluaran biaya sehingga terjadi peningkatan biaya dalam satu periode.

\section{METODE PENELITIAN}

Jenis data terbagi atas dua yaitu data kualitatif dan data kuantitatif. Data kualitatif adalah data yang dinyatakan dalam bentuk angka dan kalimat. Sedangkan data kuantitatif adalah data yang berbentuk angka atau data kualitatif yang diangkakan [5]. Adapun jenis data yang digunakan dalam penelitian ini adalah data kualitatif yaitu data berupa laporan keuangan dan keterangan-keterangan tambahan berupa penjelasan tentang laporan tersebut, dandata kuantitatif yaitu data yang berupa informasi atau penjelasan dari pihakpihak perusahaan yang relevan dengan penulisan ini.

Sumber data dibedakan menjadi dua yaitu data primer dan data sekunder. Data primer adalah sumber data penelitian yang diperoleh secara langsung dari sumber asli, sedangkan data sekunder adalah sumber data yang diperoleh secara tidak langsung melalui media perantara [6]. Data primer dalam penelitian ini, yaitu data yang diperoleh secara langsung dari pihak perusahaan pada CV. Batako Anugerah melalui wawancara langsung dengan karyawan dan manajer CV. Batako Anugerah. Sedangkan data sekunder dalam penelitian ini, yaitu data-data yang diperoleh selain dari lokasi penelitian termasuk literatur yang digunakan yang ada kaitannya dengan penelitian ini.

Populasi adalah keseluruhan objek penelitian yang memiliki karakteristik tertentu [7]. Populasi dalam penelitian ini adalah keseluruhan biaya produksi CV.Batako Anugerah. Sampel adalah sebagian atau wakil populasi yang diteliti. Jika kita hanya akan meneliti sebagian dari populasi maka penelitian tersebut disebut penelitian sampel [8]. Adapun Sampel dalam penelitian ini adalah laporan biaya produksi tahun 2018.

Metode pengumpulan data yang digunakan dalam penelitian ini adalah : observasi yaitu melakukan pengamatan langsung terhadap objek penelitian, Interview yaitu mengadakan tanya jawab atau wawancara langsung dengan pimpinan dan pegawai 
perusahaan, Dokumentasi, yaitu mengadakan pengumpulan data melalui dokumen yang berhubungan dengan materi penelitian yang akan dibahas [9].

Metode Analisis Data dalam penelitian ini adalah 'Analisa Varians' yaitu mencari selisih biaya standar dengan biaya sesungguhnya dan menganalisa sebab-sebabnya [10]. Analisa varians yang digunakan dalam pembahasan adalah ;

Varians biaya bahan baku dengan model dua selisih

1) Varians harga bahan

(harga standar-harga sesungguhnya) x kuantitas sesungguhnya.

2) Varians kuantitas bahan baku

(kuantitas standar-kuantitas sesungguhnya) x harga standar

Varians biaya tenaga kerja dengan model dua selisih

1) Varians tarif upah

Selisih tarif upah $=$ (tarif upah standar-tarif upah sesungguhnya) $\mathrm{x}$ jam kerja sesungguhnya

2) Varians efisiensi upah

Selisih efisiensi upah $=$ (jam kerja standar-jam kerja sesungguhnya $) \mathrm{x}$ upah standar

c. Varians biaya overhead pabrik

1) Varians terkendali

Biaya overhead pabrik sesungguhnya Rp. $x x x$

Biaya overhead pabrik tetap pada kapasitas normal Rp. xxx

Biaya overhead pabrik variabel sesungguhnya Rp. Xxx

Biaya overhead pabrik variabel per jam standar $\quad \underline{R p . x x x}$

Selisih terkendali Rp. Xxx

2) Varians volume

Rumus untuk menghitung selisih volume adalah sebagai berikut ;

Jam tenaga kerja pada kapasitas

Normal

xxx jam

Jam tenaga kerja standar

$\underline{\mathrm{xxx} \text { jam }}$

Selisih volume

Xxx jam

Tarif biaya overhead pabrik tetap

$\underline{\text { Rp. } x x x}$ per jam

Selisih volume

Rp. $x x x$ 
Pada varians volume ini, apabila jam tenaga kerja pada kapasitas normal lebih tinggi dari pada jam tenaga kerja standar, berarti akan terjadi varians yang merugikan. Demikian pula sebaliknya, jika jam tenaga kerja pada kapasitas normal lebih rendah dari pada jam tenaga kerja standar terjadi varians yang menguntungkan.

\section{HASIL DAN PEMBAHASAN}

\section{a. Hasil Penelitian}

Penetapan biaya standar yang disusun oleh CV. Batako Anugerah dalam memproduki Paving Block, meliputi : Standar biaya bahan baku langsung terdiri dari standar kuantitas bahan baku dan standar harga bahan baku, Standar biaya tenaga kerja langsung terdiri dari standar upah tenaga kerja dan standar efisiensi upah, standar biaya overhead pabrik terdiri dari biaya overhead pabrik variable dan biaya overhead pabrik tetap.

\section{b. Pembahasan}

\section{1) Analisa Varians Biaya Bahan Baku}

Jumlah paving block yang diproduksi pada tahun 2018 sebanyak 85.466 unit. Dalam memproduksi sejumlah unit paving block tersebut telah dikeluarkan biaya bahan baku sebesar Rp. 79.463.750. Perincian jumlah kuantitas dan biaya dari jenis bahan baku yang digunakan ini dapat dilihat pada tabel berikut:

Tabel 1. Usaha Paving Block CV. Batako Anugerah Baubau Data Jumlah Biaya Bahan Baku Tahun 2018

\begin{tabular}{|c|l|c|c|c|}
\hline No. & \multicolumn{1}{|c|}{$\begin{array}{c}\text { Jenis bahan } \\
\text { baku }\end{array}$} & $\begin{array}{c}\text { Kuantitas } \\
\text { (kg/gerobak,lt) } \\
(1)\end{array}$ & $\begin{array}{c}\text { Harga per unit } \\
(\mathrm{Rp}) \\
(2)\end{array}$ & $\begin{array}{c}\text { Biaya (Rp) } \\
3=(1 \times 2)\end{array}$ \\
\hline 1. & Pasir & 906 & 9.000 & 8.154 .000 \\
2. & Kerikil & 453 & 4.500 & 2.038 .500 \\
3. & Semen & 22.650 & 3.000 & 67.950 .000 \\
4. & Air & 5.285 & 250 & 1.321 .250 \\
\hline \multicolumn{3}{|c|}{ Total biaya bahan baku } \\
\hline
\end{tabular}

Sumber data: diolah

Dari tabel diatas dapat diketahui bahwa dalam memproduksi paving block sebanyak 85.466 unit, jumlah bahan baku pasir yang digunakan adalah sebanyak 906 gerobak dengan harga per gerobak Rp. 9.000, jumlah kerikil sebanyak 453 gerobak dengan harga per gerobak Rp. 4.500 jumlah semen yang digunakan sebanyak 22.650 
Kg dengan harga perkilo gram Rp. 3.000, dan jumlah air yang digunakan sebanyak 5.285 dengan harga per liter Rp. 250,-

Selisih antara biaya bahan baku standar dengan biaya bahan baku sesungguhnya, dapat dilihat pada tabel berikut ini:

\section{Tabel 2. Usaha Paving Block CV. Batako Anugerah Baubau Data Biaya Bahan Baku Standar dan Sesungguhnya Tahun 2018}

\begin{tabular}{|c|c|c|c|c|c|c|c|c|}
\hline \multirow{2}{*}{ No } & Jenis & \multicolumn{3}{|c|}{ Biaya bahan baku standar } & \multicolumn{2}{c|}{ Biaya bahan baku sesungguhnya } & Total selisih biaya \\
& Bahan & Kuantitas & Harga & Biaya & Kuantitas & Harga \\
baku & $(\mathrm{grb} / \mathrm{Kg})$ & $(\mathrm{Rp})$ & $(\mathrm{Rp})$ & $\begin{array}{c}\text { Biaya } \\
(\mathrm{grb} / \mathrm{Kg})\end{array}$ & $\begin{array}{c}\text { bahj baku standar } \\
\text { dengan sesungguhnya }\end{array}$ \\
\hline 1. & Pasir & 942 & 9.500 & 8.949 .000 & 906 & 9.000 & 8.154 .000 & 795.000 \\
2. & Kerikil & 489 & 5.000 & 2.445 .000 & 453 & 4.500 & 2.038 .500 & 406.500 \\
3. & Semen & 22.750 & 3.250 & 73.937 .500 & 22.650 & 3.000 & 67.950 .000 & 5.987 .500 \\
4. & Air & 6.040 & 300 & 1.812 .000 & 5.285 & 250 & 1.321 .250 & 490.000 \\
\hline \multicolumn{2}{|l}{ Jumlah } & 30.221 & 18.050 & 87.143 .500 & 29.294 & 16.750 & 79.463 .750 & 7.679 .750 \\
\hline
\end{tabular}

Sumber data : diolah

Dari tabel diatas dapat dilihat bahwa kuantitas standar untuk semua jenis bahan baku : pasir, kerikil, semen, dan air lebih tinggi dibandingkan dengan kuantitas sesungguhnya. Begitu juga halnya untuk harga bahan baku dimana harga standar lebih tinggi dari pada harga sesungguhnya. Ini berarti bahwa pada biaya bahan baku ini terdapat selisih yang lebih sebesar Rp. 7.679.750,- untuk lebih jelasnya mengenai selisih tersebut maka dapat dianalisis dengan menggunakan analisa varians yang terdiri dari :

1. Menghitung varians harga bahan baku

$$
\begin{aligned}
& \text { Pasir (HSt - HS) x KS } \\
& \text { (Rp. } 9.500-\text { Rp. 9.000) } \times 906 \quad=\text { Rp. } 453.000 \\
& \text { Kerikil (HSt - HS) x KS } \\
& \text { (Rp. } 5.000-\text { Rp. 4.500) x } 453=\text { = Rp. } 226.500 \\
& \text { Semen (HSt - HS) x KS } \\
& (\text { Rp.3.250 - Rp. 3.000) x } 22.650=\text { Rp. } 5.662 .500 \\
& \text { Air } \quad \mathrm{HSt}-\mathrm{HS}) \mathrm{x} \text { KS } \\
& \text { Jumlah } \\
& (\text { Rp.300 - Rp. 250) x } 5.285=\underline{\text { Rp. } \quad 264.250} \\
& =\text { Rp. 6.606.250 }
\end{aligned}
$$

2. Menghitung kuantitas bahan baku

$$
\begin{aligned}
\text { Pasir } & (\text { KSt }- \text { KS }) \times \text { HSt } \\
& (942-906) \times \text { Rp. } 9.500 \quad=\text { Rp. } 342.000 \\
\text { Kerikil }(\text { KSt }- \text { KS }) \times \text { HSt } &
\end{aligned}
$$


Semen (KSt - KS) x HSt

$$
(22.750-22.650) \times \text { Rp. } 3.250 \quad=\text { Rp. } 325.000
$$

Air $\quad(\mathrm{KSt}-\mathrm{KS}) \mathrm{x} \mathrm{HSt}$

$$
(6.040-5.285) \times \text { Rp. } 300
$$

Jumlah

$$
=\text { Rp. } 226.000
$$$$
=\text { Rp. } 1.073 .500
$$

Dari hasil perhitungan data yang tersedia maka dapat diketahui varians biaya bahan baku menunjukkan adanya selisih lebih, yang terdiri dari varians harga bahan baku dan varians kuantitas bahan baku sebesar Rp. 7.679.750, (Rp. 6.606.250 + Rp. 1.073.500)

\section{2) Analisa Varians Biaya Tenaga Kerja Langsung}

Untuk memproduksi 85.466 unit paving Block, jumlah biaya tenaga kerja yang dikeluarkan oleh perusahaan adalah sebesar Rp. 17.458.900,-dengan perincian sebagai berikut ;

\section{Tabel 3. Usaha Paving Block CV. Batako Anugerah Baubau Data Jumlah Biaya Tenaga Kerja Tahun 2018}

\begin{tabular}{|c|l|c|c|c|}
\hline No. & \multicolumn{1}{|c|}{ Jenis tenaga kerja } & $\begin{array}{c}\text { Jam kerja } \\
(\mathrm{jam})\end{array}$ & $\begin{array}{c}\text { Tarif } \\
\text { Upah/Jam } \\
(\mathrm{Rp})\end{array}$ & $\begin{array}{c}\text { Jumlah } \\
\text { Biaya } \\
(\mathrm{Rp})\end{array}$ \\
\hline 1. & Bagian campur & 906 & 2.200 & 1.993 .200 \\
\hline 2. & Bagian cetak & 1.057 & 5.700 & 6.024 .900 \\
\hline 3. & Bagian pembantu cetak & 1.057 & 5.100 & 5.390 .700 \\
\hline 4. & Bagian penada & 1.057 & 2.000 & 2.114 .000 \\
\hline 5. & Bagian rendam & 1.019 & 1.900 & 1.936 .100 \\
\hline \multicolumn{3}{|c|}{ Total biaya tenaga kerja } & 17.458 .900 \\
\hline
\end{tabular}

Sumber ; Data diolah

Dari tabel diatas diketahui bahwa jumlah jam kerja dan tarif upah untuk beberapa bagian berbeda. Hal ini disebabkan karena adanya tanggung jawab yang berbeda pada masing-masing bagian yang menyebabkan sistem pemberian upah juga berbeda. Untuk bagian cetak dan pembantu cetak upah diberikan berdasarkan produk yang dihasilkan per hari, sedangkan untuk bagian penadah upah diberikan berdasarkan sistem upah harian. Untuk mengetahui adanya selisih antara biaya 
tenaga kerja standar dengan biaya tenaga kerja sesungguhnya dapat dilihat pada tabel berikut ini ;

\section{Tabel 4. Usaha Paving Block CV. Batako Anugerah Baubau Data Biaya Tenaga Kerja Standar dan Sesungguhnya Tahun 2018}

\begin{tabular}{|c|c|c|c|c|c|c|c|c|}
\hline \multirow[b]{2}{*}{ No } & \multirow[b]{2}{*}{$\begin{array}{c}\text { Jenis } \\
\text { Tenaga kerja }\end{array}$} & \multicolumn{3}{|c|}{ Biaya tenaga kerja standar } & \multicolumn{3}{|c|}{$\begin{array}{l}\text { Biaya tenaga kerja } \\
\text { sesungguhnya }\end{array}$} & \multirow{2}{*}{$\begin{array}{c}\text { Total selisih } \\
\text { biaya tenaga } \\
\text { kerja standar } \\
\text { dengan } \\
\text { sesungguhny } \\
\text { a }\end{array}$} \\
\hline & & $\begin{array}{l}\text { Jam } \\
\text { kerja }\end{array}$ & $\begin{array}{c}\text { Tarif upah } \\
\text { /jam } \\
\text { (Rp) }\end{array}$ & $\begin{array}{l}\text { Biaya } \\
\text { (Rp) }\end{array}$ & $\begin{array}{l}\text { Jam } \\
\text { kerja }\end{array}$ & $\begin{array}{c}\text { Tarif upah } \\
\text { /jam } \\
\text { (Rp) }\end{array}$ & $\begin{array}{l}\text { Biaya } \\
\text { (Rp) }\end{array}$ & \\
\hline 1. & Pencampur & 943 & 2.500 & 2.357 .500 & 906 & 2.200 & 1.993 .200 & 364.300 \\
\hline 2. & Pencetak & 1.094 & 6.000 & 6.564 .000 & 1.057 & 5.700 & 6.024 .900 & 539.100 \\
\hline 3. & Pembantu cetak & 1.094 & 5.250 & 5.743 .500 & 1.057 & 5.100 & 5.390 .700 & 352.800 \\
\hline 4. & Penadah & 1.094 & 2.200 & 2.406 .800 & 1.057 & 2.000 & 2.114 .000 & 292.800 \\
\hline 5. & Perendam & 1.090 & 2.100 & 2.289 .000 & 1.019 & 1.900 & 1.936 .100 & 352.900 \\
\hline & Jumlah & 5.315 & 18.050 & 19.360 .800 & 5.096 & 16.900 & 17.458 .900 & 1.901 .900 \\
\hline
\end{tabular}

Sumber data : diolah

Dari tabel diatas dapat dilihat bahwa total selisih antara biaya tenaga kerja standar dengan biaya tenaga kerja sesungguhnya adalah sebesar Rp. 1.901.900,dimana selisih ini menguntungkan pihak perusahaan. Untuk mengetahui berapa besar selisih yang menguntungkan ini

Perhitungan varians tarif upah, untuk bagian pencetak dan pembantu cetak tidak terdapat varians, ini terjadi karena sistem pemberian upah untuk kedua bagian ini didasarkan pada jumlah paving block yang dihasilkan tiap harinya. Sedang untuk bagian pencampur, penadah dan perendaman menunjukkan adanya varians sebesar Rp. 687.000 oleh pihak perusahaan adanya varians ini menguntungkan, karena biaya standar lebih tinggi dari pada biaya sesungguhnya.

Perhitungan varians efisiensi upah menunjukkan adanya selisih antara bagian pencampur, bagian pencetak, bagian pembantu cetak, bagian penadah, dan bagian perendaman sebesar Rp. 739.250,-

Dari analisis biaya tenaga kerja standar, maka dapat diketahui jumlah varians biaya tenaga kerja standar yang terdiri atas varians tarif upah dan varians efisiensi upah sebesar Rp. 1.426.250,-

Biaya overhead pabrik yang dikeluarkan oleh perusahaan dalam memproduksi 85.466 unit paving block adalah sebesar Rp.9.762.275 dengan perincian sebagai berikut : 


\section{Tabel 5. Usaha Paving Block CV. Batako Anugerah Baubau Data Biaya Overhead Pabrik Standar dan Sesungguhnya Tahun 2018}

\begin{tabular}{|l|c|c|c|}
\hline \multicolumn{3}{|c|}{ Kapasitas normal 5.435 jam } & \multicolumn{2}{c|}{$\begin{array}{c}\text { Selisih } \\
\text { (Rp) }\end{array}$} \\
\hline \multicolumn{1}{|c|}{ Elemen biaya } & $\begin{array}{c}\text { Standar } \\
(\mathrm{Rp})\end{array}$ & & \\
\hline Biaya overhead pabrik variable & & & 50.000 \\
$-\quad$ Biaya listrik & 2.900 .000 & 2.850 .000 & 100.000 \\
$-\quad$ Biaya tenaga kerja tidak langsung & 1.600 .000 & 1.500 .000 & $\mathbf{1 5 0 . 0 0 0}$ \\
$\quad$ Total BOP variabel & $\mathbf{4 . 5 0 0 . 0 0 0}$ & $\mathbf{4 . 3 5 0 . 0 0 0}$ & 8.119 \\
Biaya overhead pabrik tetap & & & 50.000 \\
$-\quad$ Pajak & 1.282 .844 & 1.274 .725 & 23.000 \\
$-\quad$ Penyusutan aktiva tetap & 1.050 .000 & 1.000 .000 & 143.500 \\
$-\quad$ Reparasi dan pemeliharaan & 1.650 .000 & 1.627 .000 & $\mathbf{2 2 4 . 6 1 9}$ \\
$-\quad$ Kesejahteraan karyawan & 1.653 .500 & 1.510 .000 & $\mathbf{3 7 4 . 6 1 9}$ \\
\hline$\quad$ Total BOP tetap & $\mathbf{5 . 6 3 6 . 3 4 4}$ & $\mathbf{5 . 4 1 2 . 2 7 5}$ & $\mathbf{9 . 7 6 2 . 2 7 5}$ \\
\hline
\end{tabular}

Sumber ; Data Diolah

Dari tabel tersebut diatas iketahui bahwa semua elemen biaya overhead pabrik baik itu biaya overhead pabrik variabel maupun biaya overhead pabrik tetap menunjukkan adanya selisih lebih karena biaya standar yang ditetapkan terlebih dahulu lebih tinggi dibandingkan dengan biaya yang sesungguhnya terjadi . ini berarti bahwa pihak manajemen dalam melakukan perencanaan biaya, berdasarkan pada data-data historis yang ada. Perusahaan dalam menjalankan kegiatan produksinya telah menetapkan kapasitas normal yang digunakan adalah 5.435 jam.

Tarif biaya overhead pabrik baik tetap maupun variabel maka dapat dihitung sebagai berikut;

Tarif overhead pabrik variabel $=\frac{\text { total overhead variabel }}{\text { jam kerja pada kapasitas normal }}$

$=\frac{R p \cdot 4.350 .000}{5.435}$

$=$ Rp. 800,36

Tarif overhead pabrik tetap

$$
\begin{aligned}
& =\frac{\text { total overhead tetap }}{\text { jam kerja pada kapasitas normal }} \\
& =\frac{R p \cdot 5.412 .275}{5.435} \\
& =\text { Rp. } 995,81
\end{aligned}
$$


Dari hasil perhitungan data-data tersebut maka dapat diketahui varians biaya overhead pabrik menunjukkan adanya selisih lebih sebesar Rp. 215.631,4 yang terdiri dari selisih terkendalikan dan selisih volume.

\section{3) Akuntansi Biaya Standar (Metode Ganda)}

Dalam metode ganda rekening barang dalam proses dicetak angka ganda, sebelah debit diisi dengan biaya standar. Dalam metode ini, penyimpangan biaya sesungguhnya dari biaya standar dihitung pada akhir periode akuntansi. Selisih biaya sesungguhnya dari biaya standar merupakan jumlah total perbedaan antara biaya standar dengan biaya sesungguhnya.

\section{Pencatatan Biaya Bahan Baku}

Barang dalam proses - Biaya Bahan Baku Rp. 79.463.750

Persediaan bahan baku Rp.79.463.750

Pencatatan Biaya Tenaga Kerja Langsung

Barang dalam proses - Biaya tenaga kerja Rp. 17.458.900

Gaji dan Upah

Rp.17.458.900

\section{Pencatatan Biaya Overhead Pabrik}

Biaya overhead pabrik sesungguhnya

Berbagai rekening yang dikredit

Rp. 9.762 .275

(biaya overhead pabrik sesungguhnya terjadi)

Rp.9.762.275

Pada akhir periode biaya overhead pabrik yang sesungguhnya terjadi tersebut dibebankan ke produksi.

\section{KESIMPULAN}

Berdasarkan hasil penelitian dan pembahasan dapat disimpulkan bahwa, antara biaya standar yang ditetapkan oleh perusahaan dengan biaya sesungguhnya terdapat selisih lebih hal ini didasarkan pada hasil analisa bahwa Pada analisa varians biaya bahan baku, menunjukkan adanya selisih lebih, yang terdiri dari :Varians biaya bahan baku, sebesar Rp. 6.606.250 dan Varians kuantitas bahan baku sebesar Rp.1.073.500. Selisih lebih ini disebabkan karena dalam melakukan pembelian bahan baku pihak perusahaan telah memprediksikan adanya variasi harga yang akan terjadi dalam kegiatan produksi, Bahanbahan baku yang ada dimanfaatkan dan diolah dengan baik oleh tenaga-tenaga yang terampil Pada analisa varians biaya tenaga kerja, menunjukkan adanya selisih lebih, yang terdiri dari : Varians tarif upah sebesar Rp. 687.000, Varians efisiensi upah sebesar Rp. 
739.250. Selisih lebih disebabkan karena Pengawasan terhadap tenaga kerja dilakukan dengan baik, Tenaga kerja yang digunakan adalah tenaga kerja yang terampil dan rajin. Dalam hal pemberian upah bagi tenaga kerja untuk bagian : pencampur, pebadah dan perendaman pemberian upah didasarkan atas upah harian, sedang untuk bagian pencetakan dan pembantu cetak, pemberian upah, didasarkan atas jumlah unit paving block yang dihasilkan perhari. Analisa biaya overhead pabrik menunjukkan adanya selisih biaya yang terkendali sebesar Rp. 96.134,2 dan selisih volume sebesar Rp. 119.497,2. CV.Batako Anugerah dalam kegiatan produksinya telah menerapkan biaya standar sebagai alat pengendalian biaya.

\section{SARAN}

Berdasarkan kesimpulan penelitian yang dilakukan maka penulis memberikan saran yaitu Perlu diadakan pengawasan yang lebih efektif lagi terhadap pembelian dan pemakaian bahan baku, penggunaan tenaga kerja dan overhead pabrik untuk mencegah terjadinya pemborosan serta persediaan yang menumpuk. Sebaiknya pihak manajemen dalam menetapkan biaya standar sebagai alat pengendalian biaya tetap memperhitungkan dan memperhatikan biaya-biaya histories.

\section{DAFTAR PUSTAKA}

[1] Kamarudin, Ahmad. 2011. Akuntansi Manajemen: Dasar-dasar Konsep Biaya dan Pengambilan Keputusan, Cetakan Ketujuh. Jakarta: Rajawali Pers.

[2] Witjaksono, Armanto. 2013. Akuntansi Biaya.Yogyakarta: Graha Ilmu.

[3] Mulyadi. 2014. Akuntansi Biaya Edisi Kelima Cetakan Sebelas. Yogyakarta: STIM YKPN

[4] Hansen. D.R dan M.M.Mowen. 2009.Akuntansi Manajerial.Jakarta: Salemba Empat.

[5] Sugiyono. 2013. Metode Penelitian Bisnis.Bandung: Alfabeta.

[6] Indriantoro,Nur. 2009. Penelitian Bisnis untuk Akuntansi dan Manajemen Edisi 2, Yogyakarta: BPFE.

[7] Usman Rianse, dan Abdi. 2008. Metodologi Penelitian Sosial dan Ekonomi: Teori Aplikasi. Bandung: Alfabeta.

[8] Arikunto, Suharsimi. 2013. Prosedur Penelitian Suatu Pendekatan Praktek.Jakarta: Rineka Cipta.

[9] Riduan dan Sunarto. 2011. Pengantar Statistika Untuk Penelitian Pendidikan, Sosial, Ekonomi, Komunikasi, dan Bisnis.Bandung: Alfabeta.

[10] Samryn.L.M. 2012. Akuntansi Manajemen Edisi Revisi. Jakarta: Kencana Prenadamedia Group. 